\title{
Characteristics of Indoor Flood Fatalities: Evidence from Greece
}

\author{
Michalis Diakakis ${ }^{1, * \mathbb{D}}$ and Katerina Papagiannaki ${ }^{2}$ (D) \\ 1 Faculty of Geology and Geoenvironment, National and Kapodistrian University of Athens, \\ 15784 Zografou, Greece \\ 2 Institute for Environmental Research and Sustainable Development, National Observatory of Athens, \\ 11810 Athens, Greece; katpap@noa.gr \\ * Correspondence: diakakism@geol.uoa.gr
}

\begin{abstract}
Despite the important advances in flood forecasting and protection, floods remain one of the most lethal types of natural hazards. Previous works have explored several factors influencing the risks of flooding to human life and health. However, there is limited research and understanding on indoor flood fatalities and the circumstances under which they occur. This study explores victim-, building-, and situation-related characteristics in order to provide a better understanding of the conditions that lead to flood-related indoor deaths, exploiting a fatality database developed for Greece (1960-2020). The correlation analysis showed that indoor victims, compared with outdoor ones, tend to be older individuals, with high percentages of disabilities. A significant statistical association of the building material, roof type, and distance from the river with the building collapse was also found. The profile of the buildings in which flood fatality occurred was further compared with that of neighboring non-fatal buildings that were inhabited during the flood events. The statistical results indicated that the buildings with a fatality occurrence are mostly single-storey structures, made from masonry as the main building material. The findings have practical implications in risk communication and mitigation in terms of identifying the specific populations, circumstances, settings, and mechanisms that lead to dangerous indoor situations during flooding events.
\end{abstract}

Citation: Diakakis, M.;
Papagiannaki, K. Characteristics of Indoor Flood Fatalities: Evidence from Greece. Sustainability 2021, 13, 8612. https://doi.org/10.3390/ su13158612

Academic Editor: Antonio Miguel Martínez-Graña

Received: 8 July 2021

Accepted: 30 July 2021

Published: 2 August 2021

Publisher's Note: MDPI stays neutral with regard to jurisdictional claims in published maps and institutional affiliations.

\section{Introduction}

Floods are one of the most destructive and lethal natural hazards on a global level. Despite the noteworthy advances in the last few decades in warning systems [1,2], flood risk management approaches [3], and research on and the integration of new technologies (e.g., remote sensing) [4,5], floods continue to pose a significant, persistent, and possibly rising threat to human health [6,7].

Recently, numerous studies have provided a foundation of scientific knowledge on the role of different factors on flood mortality, highlighting the influence of demographics [8,9], the surrounding environment [10], infrastructural elements [11], vehicle use [12], behavioral components $[13,14]$, and other parameters that define or influence the conditions under which flood deaths occur.

Most studies have focused more on analyzing temporal, spatial, and seasonal trends of mortality at regional [7] and national scales [15,16] in an effort to define and quantify the problem. Previous works have focused predominantly on outdoor flood risks, shedding light on behavioral aspects, especially related to driving through flooded areas [17,18], evacuation choices [19], infrastructure suitability, the use of vehicles [12,20], vehicle characteristics [11,21], floodwater physical attributes and stability issues [22], and the activities of victims [8].

Recent works have shown that a portion of flood-related deaths occur indoors [23,24]. However, until today, within this literature, there have been very limited analyses and discussions on the fatalities that occur in buildings. Some studies refer to sporadic evidence of disabilities that are present in indoor incidents $[25,26]$. Old age and poor physical 
abilities have also been suggested as an influencing factor in certain works regarding indoor victims $[6,24,26-28]$. However, the existing literature does not explore the statistical significance of any of these factors' presence among victims, and provides very limited evidence on any other situational factors or elements of the built environment. For instance, while buildings' vulnerability to internal flooding risk has been linked with their characteristics [29], previous works have not explored their connection to fatal incidents.

This work focuses on indoor flood fatalities and examines the circumstances under which they occurred, aiming to improve our understanding of the role of the characteristics of buildings, the setting, and victim-related factors in these incidents, as well as to explore their association with the fatal outcome of a flood event. For this, descriptive and correlation analyses were applied to highlight potential statistically significant differences. In this context, we also examined certain characteristics of buildings that hosted a fatality in contrast with neighboring buildings that did not record any loss of life during the studied flood events, so as to better understand their effect on the occurrence or not of indoor deaths, ensuring that environmental, geomorphological, and flood-related conditions were the same and, therefore, did not affect the relationships under consideration. The practical implications of the findings regarding victim profile and building characteristics are also discussed.

\section{Materials and Methods}

\subsection{Data Collection and Approach}

This study used a flood fatalities database developed by Diakakis and Deligiannakis [30] covering the period 1960-2010, expanded for the years 2010-2020 [31]. The database contains deaths caused directly or indirectly by flooding in Greece. The database was formed using official police and fire service reports and scientific publications, as well as articles published in the press. For the purposes of this study, the database was enriched with information on the buildings in which the victims lost their lives, collected through reports, field surveys, and collected imagery (Figure 1). The table below summarizes the information on the sources and the type of data collected (Table 1), explained also in detail in the previously mentioned studies described in the database.
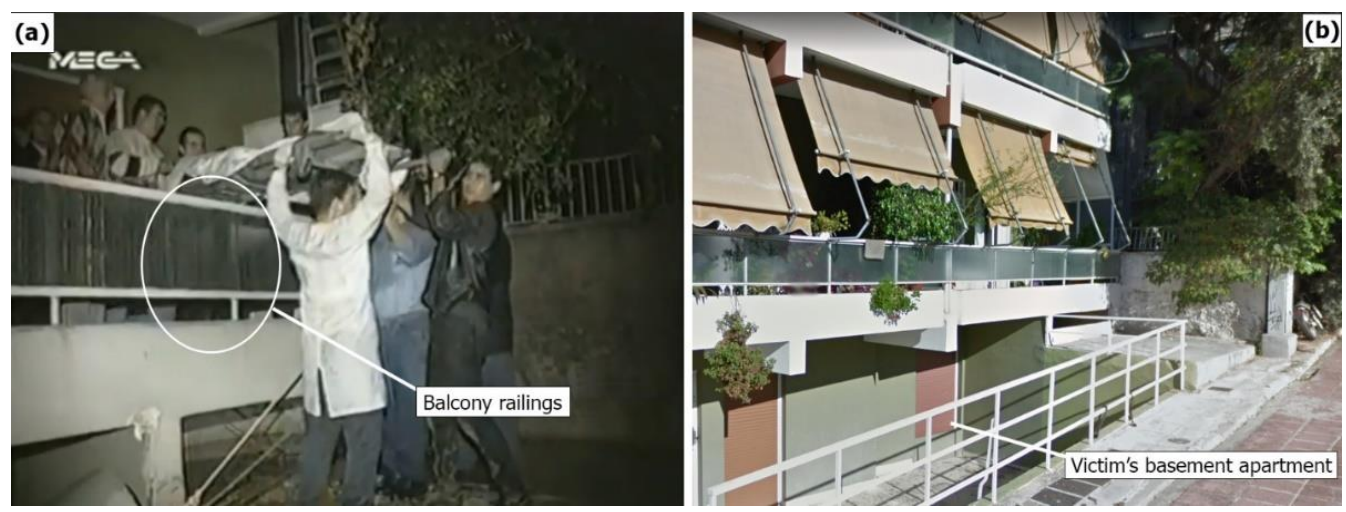

Figure 1. Example of an indoor fatal incident in 1994, in the suburb of Heraklion in Athens, Greece. The building was depicted in 1994 with TV news imagery showing the deceased carried out of it (a) and was identified through the reported address and its characteristics (e.g., balcony railings). The building was also photographed in 2021 for comparison purposes (b).

Each entry in the database corresponds to one fatality. For each fatality, we used variables to define the circumstances and the surrounding environment in which the fatal incidents occurred, as well as the actions, behavior, and demographics of the victims. The database consists of four modules denoting groups of variables, as shown in Table 2. The database also includes variables used to describe the basic characteristics of the buildings that hosted the fatalities. To ensure the accuracy and reliability of the data, information 
was included in the database only in the case that it was consistent among two or more independent sources.

Table 1. Sources of flood fatality information (1960-2020) with details of the type of information provided by each source.

\begin{tabular}{|c|c|c|}
\hline Source & Data Form & Details \\
\hline Greek Fire Service & $\begin{array}{l}\text { Incident bulletin, incident reports, and } \\
\text { press releases archive }\end{array}$ & $\begin{array}{l}\text { Accounts of the incidents containing location information } \\
\text { and details about the victims. }\end{array}$ \\
\hline Hellenic Police & Press bulletins and incident reports & $\begin{array}{l}\text { Detailed accounts of fatal incidents containing location } \\
\text { information and the timeline of events, as well as details } \\
\text { about the deceased and their actions. }\end{array}$ \\
\hline Scientific Publications & General descriptive incident accounts & $\begin{array}{l}\text { Accounts of the incidents with details on the conditions } \\
\text { under which the incidents occurred. }\end{array}$ \\
\hline Articles in the Press & $\begin{array}{l}>250 \text { articles in } 12 \text { national newspapers and } \\
\text { numerous videos from the internet and TV } \\
\text { news outlets }\end{array}$ & $\begin{array}{l}\text { Detailed accounts of the incidents containing location } \\
\text { information and visual material, sometimes accompanied } \\
\text { by eyewitness accounts. }\end{array}$ \\
\hline
\end{tabular}

Table 2. Structure of the database developed in four modules.

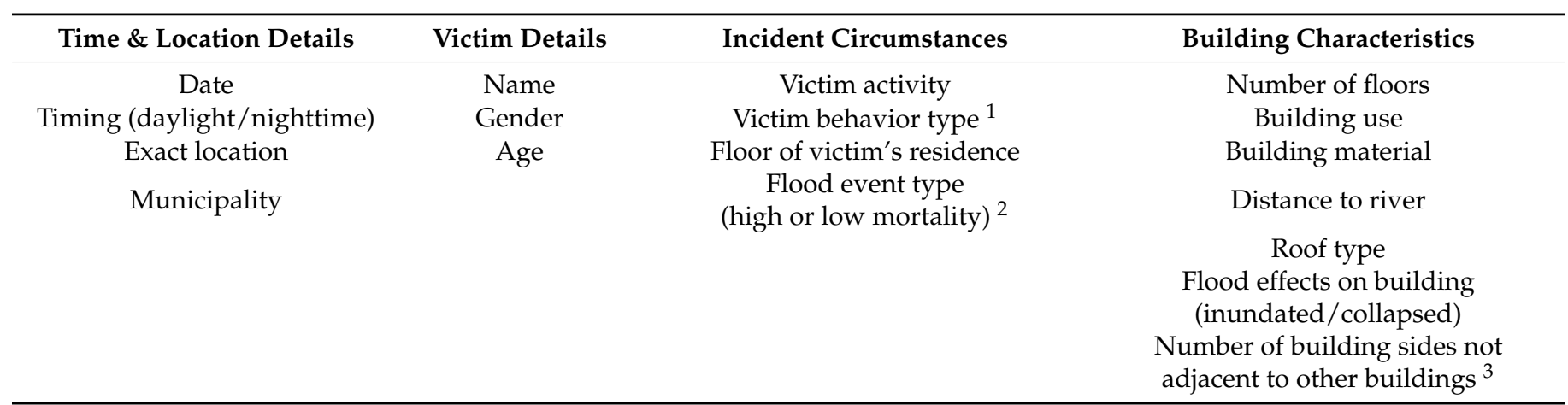

${ }^{1}$ As described by Diakakis [31] and illustrated in Table 3. ${ }^{2}$ As described by Vinet et al. [32], it us assumed that "high-mortality" events recorded over 10 fatalities while "low-mortality" events recorded less than 10 fatalities. ${ }^{3}$ The number of adjacent sides is used as an indicator of adjacency to other properties.

Table 3. Classification of behaviors in groups and different actions, motivations, and reasoning for victim actions, developed by Diakakis (31).

\begin{tabular}{|c|c|c|c|}
\hline Group Name & Main Characteristics of Behavior & Code & Reported Actions/Motivation/Reasoning for Victim's Actions \\
\hline $\begin{array}{l}\text { Deliberately } \\
\text { Active } \\
\text { (DA) }\end{array}$ & $\begin{array}{l}\text { (i) Contact with or approach to } \\
\text { floodwaters is deliberate. } \\
\text { (ii) Before contact, as decision is made, the } \\
\text { victim is in a safe position or location. }\end{array}$ & $\begin{array}{l}\text { DA1 } \\
\text { DA2 } \\
\text { DA3 } \\
\text { DA4 } \\
\text { DA5 } \\
\text { DA6 } \\
\text { DA7 } \\
\text { DA8 } \\
\text { DA9 } \\
\text { DA10 }\end{array}$ & $\begin{array}{c}\text { Enter floodwaters voluntarily to travel across/reach a destination } \\
\text { Enter floodwaters voluntarily to retrieve property/animals } \\
\text { Enter floodwaters voluntarily to rescue/assist someone } \\
\text { Stand/walk/drive at the boundary of floodwaters or on a bridge } \\
\text { to observe ("flood tourism") } \\
\text { Enter floodwaters because of occupational duty } \\
\text { Enter floodwaters voluntarily for recreational purposes } \\
\text { Enter floodwaters to check flood damage } \\
\text { Enter floodwaters as a passenger of a vehicle in which somebody } \\
\text { else is driving } \\
\text { Decision to stay/refuse evacuation to protect property or person } \\
\text { Decision to delay evacuation temporarily to protect } \\
\text { property/person or to retrieve something }\end{array}$ \\
\hline Passive $(\mathrm{P})$ & $\begin{array}{l}\text { (i) Contact with or approach to } \\
\text { floodwaters is not deliberate } \\
\text { (ii) Before contact the victim is in an initial } \\
\text { position where safety is compromised or } \\
\text { safety levels are reducing } \\
\text { (iii) Have not received any warnings }\end{array}$ & $\begin{array}{l}\text { P1 } \\
\text { P2 } \\
\text { P3 } \\
\text { P4 } \\
\text { P5 }\end{array}$ & $\begin{array}{c}\text { Decision to stay at location as it is the safest option } \\
\text { Aware of risk but impossible to evacuate because of physical } \\
\text { condition (i.e., immobile, bedridden, and others) } \\
\text { Unaware of risk until impossible to evacuate/ until accident } \\
\text { happened } \\
\text { Enter waterbody unaware of flood/before flood occurs } \\
\text { Enter floodwaters while fleeing from danger }\end{array}$ \\
\hline
\end{tabular}

Building data were aggregated through field inspections, except for $21 \%$ of the cases where we collected and examined imagery through Google Street View. Google Street View (or GSV) is a free-license online application (found in maps.google.com, accessed on 
15 July 2021) containing street-level imagery [33]. GSV's images have been used before to obtain external building and neighborhood characteristics [34,35].

Buildings that did not record fatalities during the studied flood events were also selected for comparison purposes. We examined the adjacent buildings or buildings exactly opposite the ones where the fatality occurred. With this approach, we intended to highlight the role of intrinsic building characteristics in fatal incidents by minimizing differences derived from the environment (i.e., geomorphology) and the physical properties of floodwaters (e.g., flood depth). In simple words, to compare the influence of building characteristics between the buildings of the fatal incidents with the others that did not record any fatalities, we limited variations in the environmental circumstances at a minimum per pair of buildings by studying the adjacent structures, and examining a pair in each case. Through interviews with local residents, we ensured that all the buildings studied hosted residents at the time of the flood.

To assess the behavior of the victims around floodwaters, we divided their actions into two major groups containing a total of 15 sub-categories. The main concept of the classification was the distinction between victims who came in contact with floodwaters deliberately, while they were in an initial position of safety, and victims who came in contact with floodwaters inadvertently while trapped or waiting to be rescued. The classification system was developed by Diakakis [31] in a way that the boundaries of different behavior groups were defined by objective factors (i.e., the victim's reported actions and decisions). The table below shows the full classification of behavior types (Table 3).

\subsection{Statistical Analyses}

A descriptive statistical analysis was first applied to describe the victims' profile, death circumstances, and building characteristics. Correlation analyses were then performed to examine the relationships between the variables of indoor fatalities, in order to initially highlight the conditions and building characteristics most associated with fatal situations, including building collapse. The non-parametric Pearson's Chi-square test was used to measure the significance of the association between categorical variables, followed by Cramer's V to test the strength of association. Spearman's rho was estimated for ordinal and continuous variables. The level of confidence of all statistical analyses was $95 \%$. Given the small sample size, in order to ensure statistical validity, the Chi-square test was applied only under the condition that the expected value in each cell of the variables' contingency table was 5 or more [36].

To further examine the effects of building characteristics on the fatal event due to flooding, we applied statistical analysis to the dependent building samples (1-1 paired), with the occurrence of a fatality in the building being the dependent variable. Specifically, two samples emerged from pairs of exactly adjacent/nearest occupied buildings, one of which is associated with death due to flooding. The weather-related and flood conditions, as well as the location and the geomorphological features, are therefore the same, while the building characteristics were examined for association with fatality occurrence. The final data set consisted of 31 pairs of buildings within which fatal incidents occurred (hereafter FB) versus buildings that had no fatalities (hereafter NFB) (i.e., 62 buildings, 1-1 paired). As no specific information was available on the inhabitants of NFBs, it was not possible to examine the demographic and behavioral data regarding the fatal outcome between the two groups (FBs and NFBs). To test the associations between the categorical or ordinal measures of building characteristics and the dichotomous outcome variable of fatality occurrence $(0=\mathrm{NFB}, 1=\mathrm{FB})$, Pearson's Chi-square, Cramer's V, and Spearman's rho were estimated accordingly. The synergistic effects of the building characteristics on the outcome were also examined. In the case of missing data for a building characteristic, the corresponding pair of buildings were excluded from the respective analysis. 


\subsection{Uncertainties and Limitations}

One of the limitations of the study, with regard to building analysis, was that it did not consider their internal characteristics that had the potential to influence the processes of internal flooding, such as wall, masonry and mortar voids, pipes that may experience backflow of drainage, elevators shafts, and others, as they were not visible through external building inspection and imagery.

Furthermore, in a portion of cases, the collected imagery through Google Street View did not depict part of the buildings under study due to lack of coverage. In all of these cases, we collected information for the characteristics of the building through field surveys.

Another notable limitation of the FBs versus NFBs analysis is related to the absence of analysis on the human factor, as the demographic or behavioral elements may have interacted with the building or situational factors. The reason is the unavailability of such data for NFBs. In any case, the applied statistical analysis eliminated the effect of all non-human parameters except the building, highlighting the significant effect of the latter independent of the surrounding conditions, such as water depth, flow velocity, visibility, local geomorphological vulnerability, and flood defenses.

All the deaths included in the analyses related to the building characteristics were directly connected and attributable to flooding. Fatalities caused indirectly (e.g., deaths that happened during cleanup) were not included, as the fatal incidents were not relevant to the circumstances caused by the interaction between floodwaters and the characteristics of the building. Long-term health effects were also not included in this study, as no data were available.

\section{Results}

\subsection{Analysis of Indoor Fatalities}

\subsubsection{Victim-Related Features}

The study identified 61 indoor fatalities out of 225 flood-related deaths between 1961 and 2020 for which the surroundings of the fatal incidents are known. Amongst these 61 deaths, two were connected to clean-up efforts and were thus associated indirectly with the damage caused by a flood event. All the rest were directly attributed to floodwaters.

Among the 61 victims, 34 were males (55.7\%) and 27 were females $(44.3 \%)$, with an average age of 57 years old. Although there was a slightly higher percentage of female victims among the indoor fatalities (44.3\%) compared with outdoor incidents $(31.9 \%)$, the difference was not statistically significant at the $5 \%$ level $(p=0.09)$. On the contrary, age showed a statistically significant correlation with whether the victim died indoors or outdoors (Spearman's rho $=0.25, p<0.001$ ), supporting the hypothesis that indoor victims tend to be older compared with individuals that pass away outdoors from flooding (Table 4).

Table 4. Demographic details of the victims (gender and age) in relation to the surroundings in which the fatal incidents occurred (indoors/outdoors).

\begin{tabular}{cccccc}
\hline & & Outdoors & Indoors & Total & Association Test \\
\hline \multirow{3}{*}{ Gender } & Female & 51 & 27 & 78 & Chi-square $=2.97$ \\
& Male & 109 & 34 & 143 & $\mathrm{df}=1$ \\
\multirow{3}{*}{ Age } & Total & 160 & 61 & $\mathrm{~N}=221$ & $p=0.09$ \\
& & $43.8^{1}$ & $57.1^{1}$ & $\mathrm{~N}=213$ & $\begin{array}{c}\text { Spearman's rho }=0.25 \\
p<0.001\end{array}$ \\
\hline
\end{tabular}

${ }^{1}$ Average age.

Indoor fatalities were found to occur in a higher percentage during high-mortality flood events ( $>10$ deaths), showing a statistically significant difference $(p<0.01$; Table 5$)$. 
Table 5. Distribution of fatalities in high- and low-mortality flood events in relation to the surroundings in which the respective fatal incidents occurred (indoors/outdoors; $\mathrm{N}=225$ ).

\begin{tabular}{cccc}
\hline & $\begin{array}{c}\text { High-Mortality Events } \\
(>\mathbf{1 0} \text { Deaths })\end{array}$ & $\begin{array}{c}\text { Low-Mortality Events } \\
\text { (<10 Deaths })\end{array}$ & Association Test \\
\hline \multirow{2}{*}{ Indoors } & 30 & 31 & Chi-square $=10.06$ \\
Outdoors & 44 & 120 & $\mathrm{df}=1$ \\
& & & $p<0.01$ \\
\hline
\end{tabular}

Among indoor victims, we found a statistically significant difference of individuals with disabilities in comparison with victims of outdoor incidents (Chi-square $=31.09, \mathrm{df}=1$, $p<0.001$ ), with an impressive percentage overall (11 out of 61 or $18 \%$ ). For comparison purposes, we note that in Greece, mobility- and sensory-related disabilities do not surpass $6.3 \%$ of the total population [37].

Regarding the actions of the victims, we found that the vast majority ( $86.9 \%)$ pursued a "passive" behavior (Table 6). This indicates that the victims came in contact with floodwaters mostly inadvertently, in the sense that they were forced by the circumstances and they were trapped, as they were unable to flee or evacuate the building in time. There were no cases where a victim died during an effort to rescue someone. In only two of the cases, the victims either delayed evacuation temporarily to retrieve valuables or decided to stay because they considered it the safest option. In these last two cases, the victims were considered to have a deliberate contact with floodwaters. In essence, this shows a higher percentage of active behavior and deliberate contact with floodwaters in outdoors flood-related fatal incidents with a statistically significant difference (Pearson Chi-square $=123.10, \mathrm{df}=1, p<0.001$ ).

Table 6. Types of behavior pursued by the indoor victims at the time of the fatal incidents based on the categorization suggested by Diakakis (31). "P" denotes passive behavior, whereas "DA" denotes deliberately active behavior.

\begin{tabular}{|c|c|c|}
\hline Behavior Types & Number & Percentage $(\%)$ \\
\hline P1. Decision to stay at the location as the safest option & 5 & 8.2 \\
\hline $\begin{array}{l}\text { P2. Aware of risk, but impossible to evacuate because of physical condition (i.e., immobile, } \\
\text { bedridden, and others) }\end{array}$ & 9 & 14.8 \\
\hline P3. Unaware of risk until impossible to evacuate/or until the accident happened & 39 & 63.9 \\
\hline P4. Enter waterbody unaware of flood/before flood occurs & 0 & 0.0 \\
\hline P5. Enter floodwaters while fleeing from danger & 0 & 0.0 \\
\hline DA9. Decision to stay/refuse evacuation to protect property or person & 1 & 1.6 \\
\hline $\begin{array}{c}\text { DA10. Decision to delay evacuation temporarily to protect property/person or to retrieve } \\
\text { something }\end{array}$ & 1 & 1.6 \\
\hline Not reported or not applicable & 6 & 9.8 \\
\hline Total & 61 & 100.0 \\
\hline
\end{tabular}

\subsubsection{Characteristics of Buildings with Fatalities}

With respect to the FBs, namely the buildings in which the fatal incidents occurred (Table 7), we found that all victims for whom the floor of residence was known lived on ground or below-ground floors, in mostly one-storey structures (64\%).

Approximately a quarter $(23 \%)$ of the FBs collapsed completely or partially with supporting elements breaking down. The majority of these structures were residential, followed by commercial buildings and nursing homes in smaller percentages.

Structurally, the examined FBs were mostly made of reinforced concrete (RC) or masonry/mixed methods $(\mathrm{M})$, while their roofs were made of either ceramic tiles $(41 \%)$, or concrete slabs to a slightly smaller percentage (36.1\%).

Examination of the structures' contact with adjacent properties showed that a significant portion (around 60\%) of the FBs had three or four open sides, indicating some level of isolation in terms of evacuating or receiving rescue from the adjacent property. 
Table 7. Distribution of building characteristics and of the victim's position in the buildings in which fatal incidents took place (FBs).

\begin{tabular}{|c|c|c|c|}
\hline Building Characteristic & & Number & Percentage $(\%)$ \\
\hline \multirow{5}{*}{ Floor of victim's residence Outdoors } & Below ground & 20 & 32.8 \\
\hline & Ground floor & 33 & 54.1 \\
\hline & First floor & 0 & 0.0 \\
\hline & Not reported & 8 & 13.1 \\
\hline & Total & 61 & 100.00 \\
\hline \multirow{7}{*}{ Building number of floors } & 1 & 39 & 63.9 \\
\hline & 2 & 8 & 13.1 \\
\hline & 3 & 1 & 1.6 \\
\hline & 4 & 0 & 0.0 \\
\hline & 5 & 3 & 4.9 \\
\hline & Not reported & 10 & 16.4 \\
\hline & Total & 61 & 100 \\
\hline \multirow{4}{*}{ Flood effect on building } & Collapsed & 14 & 23.0 \\
\hline & Not collapsed & 37 & 60.7 \\
\hline & Not reported & 10 & 16.4 \\
\hline & Total & 61 & 100 \\
\hline \multirow{4}{*}{ Roof type } & Ceramic tiles & 25 & 41.0 \\
\hline & Concrete slab & 22 & 36.1 \\
\hline & Not reported & 14 & 23.0 \\
\hline & Total & 61 & 100 \\
\hline \multirow{5}{*}{ Building use } & Residential & 47 & 77.0 \\
\hline & Commercial & 5 & 8.2 \\
\hline & Nursing home & 3 & 4.9 \\
\hline & Not reported & 6 & 9.8 \\
\hline & Total & 61 & 100 \\
\hline \multirow{5}{*}{ Building material } & Masonry building & 15 & 24.6 \\
\hline & Armed cement & 31 & 50.8 \\
\hline & Mixed & 2 & 3.3 \\
\hline & Not reported & 13 & 21.3 \\
\hline & Total & 61 & 100 \\
\hline \multirow{6}{*}{ Number of building sides not adjacent to other buildings } & 1 & 0 & 0.0 \\
\hline & 2 & 13 & 21.3 \\
\hline & 3 & 19 & 31.1 \\
\hline & 4 & 18 & 29.5 \\
\hline & Not reported & 11 & 18.0 \\
\hline & Total & 61 & 100 \\
\hline
\end{tabular}

With regard to their distance from the river course, most of the FBs $(60 \%)$ were found within $15 \mathrm{~m}$ from the riverbanks, whereas $40 \%$ of them were situated between $20 \mathrm{~m}$ and $200 \mathrm{~m}$ from the riverbanks (Figure 2).

Table 8 presents the results of the correlations among the FB characteristics and the effect of the flood on the structure, i.e., whether the building collapsed or not. This is important in terms of the safety of the person(s) inside [38], and was found to be associated with the roof type, the building material, the open sides to the adjacent properties, and the distance from the river course. To avoid violation of the Chi-square test restrictive rules, we merged the categories of the variable building material, which was limited to two categories, namely reinforced concrete $(\mathrm{RC})$ and masonry/mixed $(\mathrm{M})$ material. 


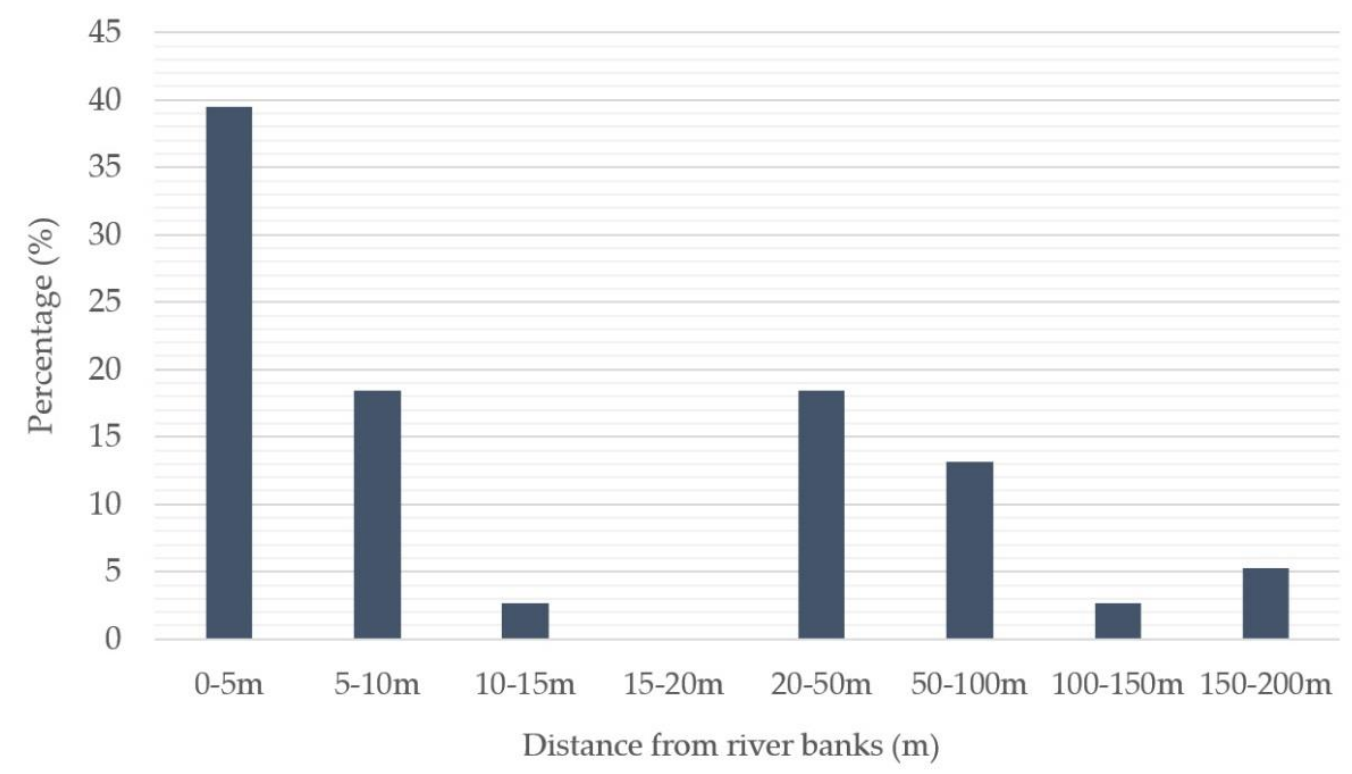

Figure 2. Percentage of fatal buildings (FBs) in relation to their distance from the riverbanks.

Table 8. Results of correlation tests between FB characteristics and flood effect, i.e., whether it collapsed or not due to the flood.

\begin{tabular}{ccc}
\hline Building Characteristic & Observations & Flood Effect \\
\hline Roof type & 45 & $0.50^{* * *}$ \\
Number of floors & 49 & + \\
Building use & 51 & + \\
Building material & 46 & $0.86^{* * *}$ \\
Open sides to adjacent properties & 48 & $0.38^{* *}$ \\
River distance & 37 & $-0.66^{* * *}$ \\
\hline
\end{tabular}

Note: Flood effect is dichotomous $(0=$ collapsed, $1=$ not collapsed $)$. For the categorical variables of roof type, building use, and building material, Cramer's V measure of the correlation strength is provided along with the respective $p$-value of the Chi-square test. For the continuous variables of the number of floors, openings, and river distance, Spearman's rho is provided, with the respective $p$-value. Significance: $+p>0.05,{ }^{* *} p<0.01,{ }^{* * *} p<0.001$.

All of the the correlations of the flood effect on the building with its characteristics were found to be statistically significant, except for those related to the number of floors and building use. The building material was found to have the strongest correlation with the flood effect (Cramer's V $=0.86, p<0.001)$. In particular, the percentage of FBs that were $\mathrm{M}$ type and collapsed was $82 \%$, unlike the RC ones, none of which collapsed (Figure 3). Regarding the type of roof, a very large percentage of collapse occurred in the FBs with ceramic tiles (52\%), while a very small percentage occurred in the buildings with a concrete slab (5\%). In terms of openings to adjacent buildings, the collapse rates were higher for a larger number of such openings. Finally, as expected, the rate of collapse of a building decreased as the distance from the center of the flood, i.e., the river or river stream, increased, as shown by the box plot distribution of distance over the flood effect, i.e., whether the building collapsed or not (Figure 4). Specifically, the average distance of FBs that collapsed from the river was $3.5 \mathrm{~m}$, while that of the FBs that did not collapse was $27.7 \mathrm{~m}$. 

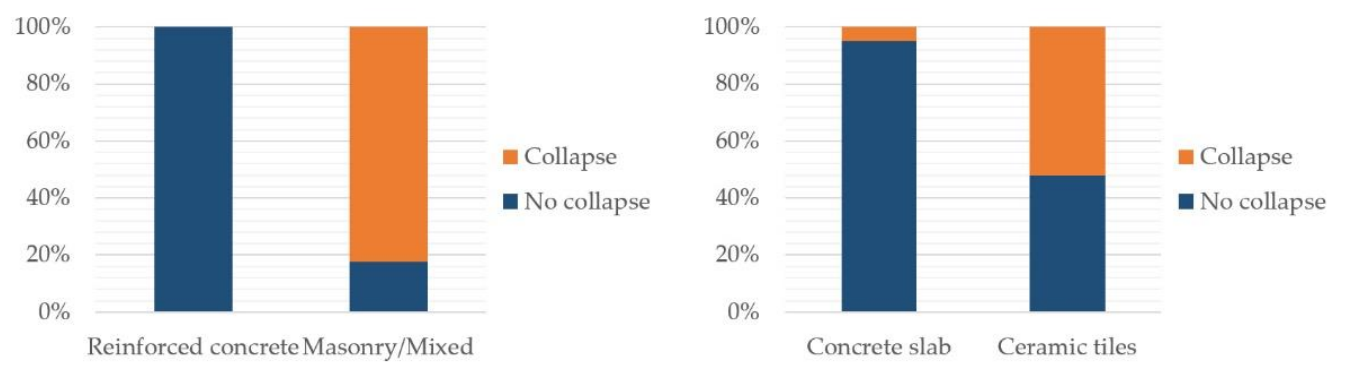

Figure 3. Distribution (\%) of FBs according to the flood effect, i.e., whether the FB collapsed or not, per building material (left) and roof type (right).

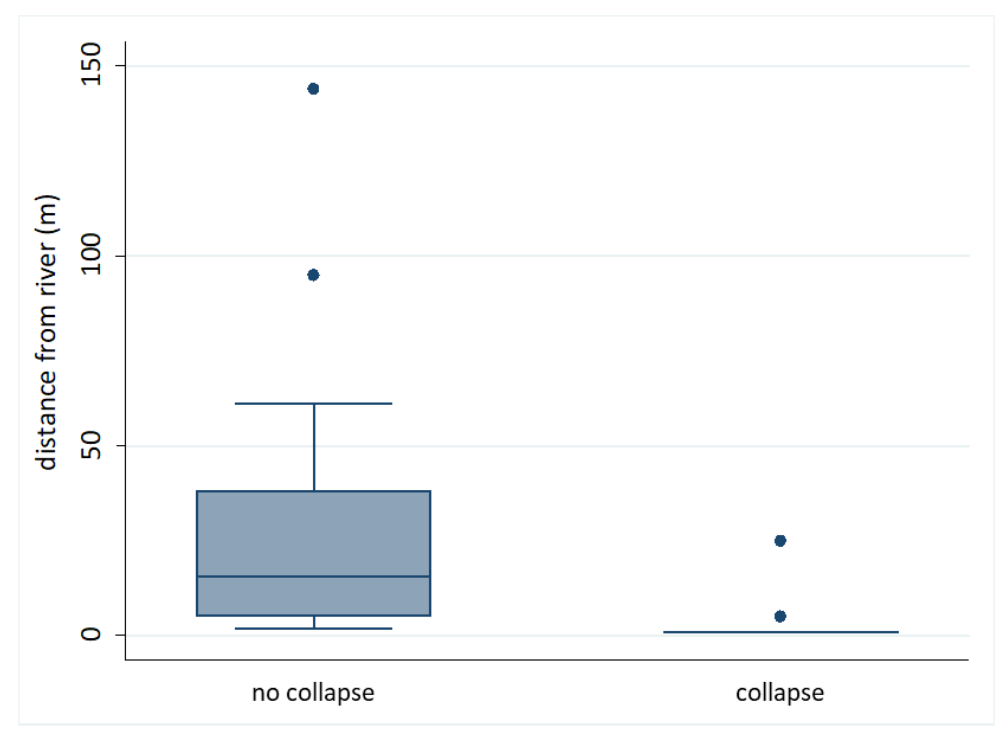

Figure 4. Distribution (box plot) of the distance from the river, over the dichotomous variable of flood effect on the FB, i.e., whether the FB collapsed or not.

\subsection{Comparison between Fatal and Non-Fatal Buildings}

The comparison of FBs-NFBs showed certain differences. Table 9 shows the statistical correlations between building characteristics and fatality occurrence $(0=\mathrm{NFB}, 1=\mathrm{FB})$. Correlations between flood effect or building use and fatality occurrence were not estimated, as the conditions for a valid Chi-square test were violated.

Table 9. Results of the correlation tests between building characteristics and fatality occurrence.

\begin{tabular}{ccc}
\hline Building Characteristic & Observations & Flood Effect \\
\hline Roof type & 58 & + \\
Number of floors & 58 & $-0.44^{* * *}$ \\
Building material & 60 & $0.30^{*}$ \\
Open sides to adjacent properties & 58 & + \\
\hline
\end{tabular}

Note: The outcome fatality occurrence is dichotomous $(0=\mathrm{NFB}, 1=\mathrm{FB})$. For the categorical variables of roof type and building material, the Cramer's V measure of the correlation strength is provided, with the respective $\mathrm{p}$-value for the Chi-square test. For the continuous variables number of floors and openings to adjacent properties, Spearman's rho is provided, with the respective $p$-value. Significance: $+p>0.05,{ }^{*} p<0.05,{ }^{* * *} p<0.001$.

The results show statistically significant correlations for the number of floors (Spearman's rho $=-0.44, p<0.001$ ) and the building material (Cramer's V $=0.30, p<0.05$ ) with fatality occurrence. As shown in Figure 5, the percentage of $M$ (masonry/mixed) type buildings was significantly higher in the sample of FBs $(30 \%)$ than in NFBs (7\%). 


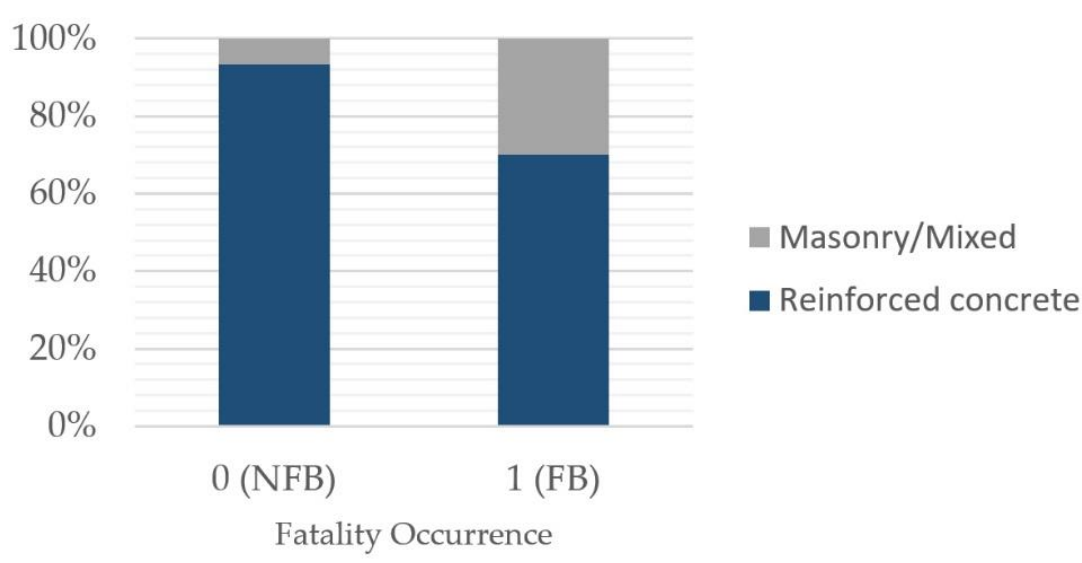

Figure 5. Distribution (\%) of buildings regarding building material, per fatality occurrence $(0=\mathrm{NFB}$, $1=\mathrm{FB})$.

Regarding the number of floors, FBs showdc higher percentages of low buildings (mostly one-storey) in comparison with NFBs.

To further examine the effects of these two important parameters, namely materials and number of floors, we also estimated their synergistic effect on fatality occurrence. For this analysis, the continuous variable number of floors was converted to an ordinal variable named building height, which had two categories, coded as 1 for high buildings $(\mathrm{H})$ with more than 1 floor and 2 for low buildings (L) with 1 floor. The variable building material was also coded as 1 for RC and 2 for $\mathrm{M}$ type. The synergistic effect of building material and height was then derived from the multiplication of the two coded variables. The Pearson Chi-square correlation between the synergistic variable of material-height and fatality occurrence (58 observations) was found to be significant $(p<0.001)$ and strong (Cramer's V $=0.54)$. As Figure 6 shows, most of the NFBs were reinforced concrete $(R C)$ and higher $(\mathrm{H})$ than 1 floor $(\mathrm{RC}-\mathrm{H}=72 \%)$, while the percentage of such buildings in the FBs was significantly lower $(\mathrm{RC}-\mathrm{H}=21 \%)$. Conversely, the percentage of buildings that combined masonry/mixed type (M) and low height (L) was very small in the NFBs $(\mathrm{M}-\mathrm{L}=3 \%)$ and significantly higher in the FBs $(\mathrm{M}-\mathrm{L}=28 \%)$.

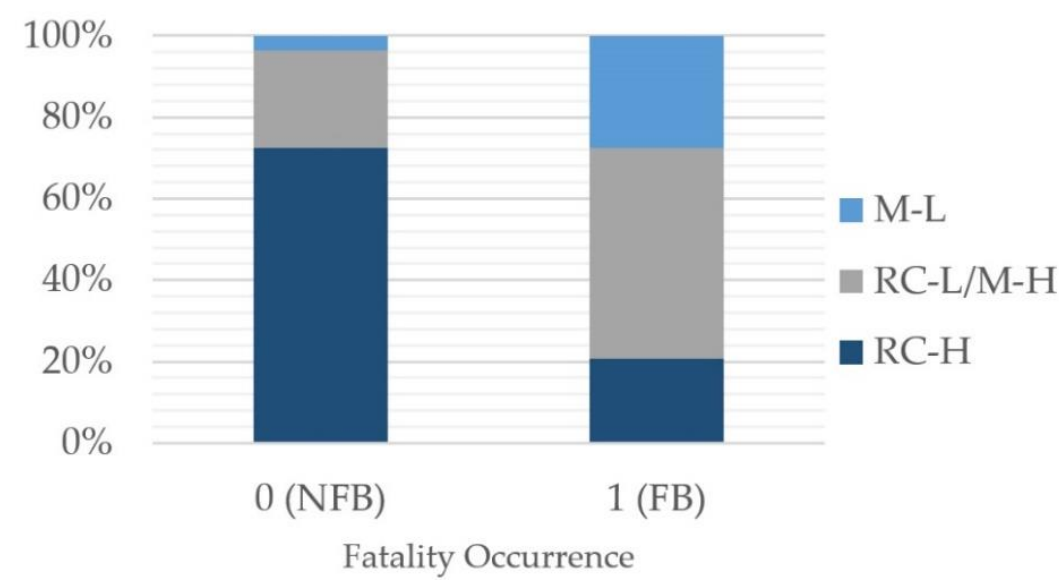

Figure 6. Distribution (\%) of buildings regarding the combination of building material (RC or $\mathrm{M}$ ) and height $(\mathrm{H}$ or $\mathrm{L})$, per fatality occurrence $(0=\mathrm{NFB}, 1=\mathrm{FB})$.

Finally, it has to be noted that $65.7 \%$ of the incidents (for which timing is known) occurred during the night. 


\section{Discussion}

This study exploits a flood mortality database for Greece (1960-2020) to examine the circumstances of indoor flood-related fatalities, including victim-, situation-, and buildingrelated characteristics. Overall, the findings show that a number of factors other than the physical attributes of the flood itself, show an association with the occurrence of these fatal incidents.

Among the examined factors, we found that certain victim characteristics, including their age, the presence of disabilities, and their behavior (as defined by their actions), show a statistically significant association with whether an individual died during a flood in an indoor or an outdoor environment.

The findings show that in indoor incidents, victims tend to be older, indicating that age is a vulnerability factor. This is in agreement with the evidence presented in previous works for indoor victims [24]. This result confirms also the suggestion of Haynes et al. [25], that sheltering indoors may not be always a viable option for people with limited mobility, including the elderly. With respect to gender, despite the difference recorded (see Table 4), it was not found to be a vulnerability factor, a result acknowledged also by Wilson [39], who examined the gender of trapped flood victims. In addition, indoor victims were found to exhibit, in their vast majority, a passive behavior in the sense of getting trapped in a building rather than deliberately engaging with floodwaters, refusing evacuation, or trying to rescue someone or something. This is a pattern echoed in previous works [26], although it has rarely been measured and confirmed with statistical significance.

Based on the abundance of disabilities among indoor victims (18\%) and the statistical association of this factor, we consider it a strong indication that disabilities play a role in how dangerous situations develop in flooded buildings.

In conjunction with the factor of old age, the findings suggest that disabilities make it more likely that individuals fail to evacuate their homes in time because of a physical inability, or to flee from danger or other comorbidities (e.g., limited sensory abilities) that make them more vulnerable [40]. The factor of limited mobility has appeared in multiple previous works [23,24]. Even in cases where vertical evacuation was available (i.e., using a stairway, certain individuals did not manage to climb up to safety. In addition, other factors may play a role, although no specific evidence was found in this study, such as poor assessment of the circumstances [41], emotional attachment to their belongings and property [42], adverse emotional effects [43], or reluctance to abandon medical or other routines [28]. In addition, the overrepresentation of older victims could be partly attributed to the fact that older people tend to reside in lower floors for accessibility reasons [44,45], given also that ground and underground floors are hit disproportionately by flooding.

Apart from the characteristics of the decedents, certain building characteristics have been shown to play a significant role in fatal outcomes. Buildings that host fatalities were found to be mostly one-storey structures. In addition, the distributions of the examined characteristics showed the clear prevalence of some of them, which were related to the collapse of the building and, therefore, to a greater risk of human losses. In particular, the contribution of the material seems to be very important, following previous studies that related the material to the quality of the building in terms of structural strength against flooding $[38,46]$. The roof was also found to be associated with collapses, with the ceramic tile roof being overrepresented in unstable buildings. It should be noted that the type of roof has a close relationship with the building material, as concrete structures are usually built with flat roofs (i.e., concrete slab) [47]. The number of open sides to adjacent properties also appeared to be statistically associated as well. It is of course very common for one-storey buildings to be surrounded by yards and to have more space between them and neighbouring buildings, as they are more often located in less urbanized areas [47], thus this could be a non-causal relationship.

The effect of the short distance from the river on the collapse of the building was also found to be very strong. This was expected, as buildings near the river course are normally subject to higher velocities [46], and suffer from foundation erosion and undercutting and 
flood depth, which in return can cause higher depth differential and lateral pressure on the walls [44].

A further analysis of the 1-1 pairs of FBs and NFBs confirmed the importance of the material. The statistical results indicated that masonry buildings are indeed associated with a higher occurrence of human loss compared with buildings made of reinforced concrete under the same surrounding conditions. The type of roof, although associated with the collapse of a building, was not found to be associated with a higher probability of human loss in the analysis of the adjacent buildings, contrary to what Vinet et al. [26] have suggested. On the contrary, the building's number of floors, although it did not seem to be related to the collapse of the building, was found to be related to loss of life, with low structures recording more fatalities. The combination of the two important building characteristics, the material and the height (number of floors), highlighted their significant synergistic effect on the overall likelihood of fatality in the building. One-storey masonry buildings can be a factor of vulnerability because of the lack of vertical evacuation routes and their tendency to collapse at a higher rate than the reinforced concrete ones. This is in agreement with evidence from the Xynthia and Var floods in France [26], as well as from the Mandra flood in Greece, which hypothesized that multiple storey building may facilitate an evacuation.

Finally, a factor related to the flood event itself and its impact (i.e., whether it is a high- or a low-mortality one) showed an association with the number of indoor victims, confirming the hypotheses made in previous works [32]. The literature does not offer any specific explanation for this pattern. One possible explanation, although no specific data are available, is related to the magnitude of the flood event. In more common events of a lower magnitude, life-threatening conditions are usually limited near the river channel or in it. In these cases, people who approach the river are more likely to be caught in the flood, either because they try to drive through, observe the situation, stand on a bridge, or use a ford crossing [31]. Most of these activities occur in outdoor settings. On the contrary, in rare events of a high magnitude, life-threatening conditions expand to locations further away from the river channel, and probably into build-up areas where they surprise the population [26], leading to multiple in-building fatalities. This finding appears to be related to a combination of vulnerability factors, likely including the abundance of nighttime incidents, which is related to the element of surprise [26], as people are commonly sleeping.

Overall, the findings reveal certain conditions or circumstances that are more common among flood-related fatal indoor incidents with statistically significant differences, indicating a correlation with dangerous situations that lead to fatalities. The victims tend to be older individuals, often with disabilities, living in ground or underground floors, getting trapped (most of the time during the night) in buildings that are in most cases one-storey structures made of masonry in an increased percentage, that suffer collapse at an increased rate in comparison with the surrounding buildings.

The evidence presented in this study also suggests a conceptual mechanism under which the indoor flood mortality is taking place. Indoor deaths occur mostly in urban areas of a higher population density, yet they are less numerous than outdoor deaths [48]. A large percentage of the population that happens to be in the area during urban flooding events is therefore saved, while only a very small fraction is caught in dangerous situations and eventually pass away because of the flood. Evacuation and building stability can be influential in this process, based on the findings of the present study that fit into the general framework put forward in previous works. Therefore, among this population, the victims tend to be those individuals who are not physically able to evacuate and/or do not have an available evacuation option (horizontal or vertical) as a result of the building characteristics or their location in it (e.g., living in a basement), or a combination of some of these factors.

In fact, considering two factors related to the victim (old age over 70-years old and presence of disabilities) and two factors related to the building (one-storey and masonry structures), we found that 54 out of the 61 cases examined (or $89 \%$ ) had at least one of these 
four vulnerability factors, while all of the victims resided on either ground or underground floors, regardless of the number of floors in their residency.

Considering the above, in terms of the practical implications of this analysis, there are vulnerability factors related to both the demographic profile and the building profile associated with indoor flood mortality. Authorities can exploit the present findings in shaping flood risk mitigation-related policy initiatives. Targeted interventions of structural flood protection measures near areas with buildings with a poor structural integrity (such as simple masonry or stone buildings) could lower the risk related to these structures. In addition, it is important to carry out informational campaigns and develop educational material (e.g., leaflets) aiming to enhance the protection of the elderly, as well as persons with disabilities, targeting both groups of the population, as well as their close relatives and caregivers, especially in high flood risk areas. Furthermore, emergency authorities and the individuals themselves [40] should consider setting up warning or emergency communication systems to communicate risk to the persons of interest, as well as to their relatives or persons who can provide them with help in times of emergency. Particular care should be given by emphasizing the importance of planning at the household level, especially for underground and ground floor properties (residential, commercial, and others). For instance, when flood or extreme weather forecasts/notices are in place, vulnerable individuals could spend their days and nights with relatives at a safer place.

Emergency personnel should be also trained accordingly in executing rescue missions in an indoor environment, with drill scenarios that reflect real-world conditions such as the ones described in the present study.

Furthermore, the results can be taken into account when estimating flood vulnerability at the building level, considering, for example, the density of low-rise masonry/mixed type buildings. Similarly, these parameters can be used to optimize life loss models [49] for areas with a similar building profile. The structural strength of the building, as well as the living conditions (i.e., one-storey or higher buildings), are suggested as important factors in the life loss estimation equation [49].

Certain limitations arise from the approach used in this work and should be noted. Primarily, it would be ideal in the future to expand the sample to other geographical areas and to extend it in terms of the absolute victim numbers used. Except for the European territory and other developed areas of the world, it would be interesting to examine the role of buildings in indoor flood mortality in areas where building codes are absent, and in communities whose buildings stocks suffer from poor structural integrity or use different materials (including wood, mudbricks, and others). In this context, the generalization of the findings regarding building characteristics should be considered with caution.

\section{Conclusions}

Improving our understanding on the circumstances of flood fatalities increases our chances to enhance the protection of human life from flooding. This study exploits a database of flood-related fatalities that occurred in Greece between 1960 and 2010, and examines the victim-, situation-, and building-related factors that have an influence on these fatal incidents, in an effort to improve our knowledge on how dangerous situations develop. The results show that a number of factors present an association with indoor mortality. Flood victims that die indoors tend to be older, often with disabilities, exhibiting a passive behavior against floodwaters, in the sense of getting trapped in ground and underground floors mostly in residential buildings. In a relatively high percentage of cases, the buildings are one-storey structures restricting vertical evacuation and, on certain occasions, they collapse as a result of the building materials used.

The results presented in this study fill the existing knowledge gap in the role of building characteristics and victim profiling on indoor fatalities, but also can be exploited to shape policy interventions aiming to increase the protection of vulnerable populations with specific and targeted initiatives. Based on the present findings, these interventions can reflect the real-world dangerous situations and vulnerabilities identified in this study. 
Author Contributions: Conceptualization, M.D. and K.P.; methodology, M.D. and K.P.; software, K.P.; validation, K.P.; formal analysis, M.D. and K.P.; investigation, M.D. and K.P.; resources, M.D.; data curation, M.D.; writing — original draft preparation, M.D. and K.P.; writing-review and editing, M.D. and K.P.; visualization, K.P. All authors have read and agreed to the published version of the manuscript.

Funding: This research received no external funding.

Institutional Review Board Statement: Not applicable.

Informed Consent Statement: Not applicable.

Data Availability Statement: The data presented in this study are available on request from the corresponding author. The data are not publicly available due to privacy issues.

Conflicts of Interest: The authors declare no conflict of interest.

\section{References}

1. Hapuarachchi, H.A.P.; Wang, Q.J.; Pagano, T.C. A review of advances in flash flood forecasting. Hydrol. Process. 2011, 25, 2771-2784. [CrossRef]

2. Emerton, R.E.; Stephens, E.M.; Pappenberger, F.; Pagano, T.C.; Weerts, A.H.; Wood, A.W.; Salamon, P.; Brown, J.D.; Hjerdt, N.; Donnelly, C.; et al. Continental and global scale flood forecasting systems. Wiley Interdiscip. Rev. Water 2016, 3, $391-418$. [CrossRef]

3. Arduino, G.; Reggiani, P.; Todini, E. Recent advances in flood forecasting and flood risk assessment. Hydrol. Earth Syst. Sci. 2005, 9, 280-284. [CrossRef]

4. Perks, M.T.; Russell, A.J.; Large, A.R.G. Technical note: Advances in flash flood monitoring using unmanned aerial vehicles (UAVs). Hydrol. Earth Syst. Sci. 2016, 20, 4005-4015. [CrossRef]

5. Wang, Y. Advances in remote sensing of flooding. Water 2015, 7, 6404-6410. [CrossRef]

6. Alderman, K.; Turner, L.R.; Tong, S. Floods and human health: A systematic review. Environ. Int. 2012, 47, 37-47. [CrossRef]

7. Paprotny, D.; Sebastian, A.; Morales-Nápoles, O.; Jonkman, S.N. Trends in flood losses in Europe over the past 150 years. Nat. Commun. 2018, 9, 1-12. [CrossRef]

8. Jonkman, S.N.; Kelman, I.; Road, S.N.J.; Deputy, I.K. An analysis of the causes and circumstances of flood disaster deaths. Disasters 2005, 29, 75-97. [CrossRef]

9. Ashley, S.T.; Ashley, W.S. Flood fatalities in the United States. J. Appl. Meteorol. Climatol. 2008, 47, 805-818. [CrossRef]

10. Salvati, P.; Petrucci, O.; Rossi, M.; Bianchi, C.; Pasqua, A.A.; Guzzetti, F. Gender, age and circumstances analysis of flood and landslide fatalities in Italy. Sci. Total Environ. 2018, 610-611, 867-879. [CrossRef]

11. Gissing, A.; Opper, S.; Tofa, M.; Coates, L.; McAneney, J. Influence of road characteristics on flood fatalities in Australia. Environ. Hazards 2019, 18, 434-445. [CrossRef]

12. Ahmed, M.A.; Haynes, K.; Taylor, M. Vehicle-related flood fatalities in Australia, 2001-2017. J. Flood Risk Manag. 2020, 13, 1-17. [CrossRef]

13. Pearson, M.; Hamilton, K. Investigating driver willingness to drive through flooded waterways. Accid. Anal. Prev. 2014, 72, 382-390. [CrossRef]

14. Hamilton, K.; Price, S.; Keech, J.J.; Peden, A.E.; Hagger, M.S. Drivers' experiences during floods: Investigating the psychological influences underpinning decisions to avoid driving through floodwater. Int. J. Disaster Risk Reduct. 2018, 28, 507-518. [CrossRef]

15. Fitzgerald, G.; Du, W.; Jamal, A.; Clark, M.; Hou, X.-Y. Flood fatalities in contemporary Australia (1997-2008). Emerg. Med. Australas. 2010, 22, 180-186. [CrossRef]

16. Špitalar, M.; Brilly, M.; Kos, D.; Žiberna, A. Analysis of Flood Fatalities-Slovenian Illustration. Water 2019, 12, 64. [CrossRef]

17. Becker, J.S.; Taylor, H.L.; Doody, B.J.; Wright, K.C.; Gruntfest, E.; Webber, D. A Review of People's Behavior in and around Floodwater. Weather Clim. Soc. 2015, 7, 321-332. [CrossRef]

18. Hamilton, K.; Demant, D.; Peden, A.; Hagger, M. A systematic review of human behaviour in and around floodwater. Int. J. Disaster Risk Reduct. 2020, 47, 101561. [CrossRef]

19. Hayes, A.F. Beyond Baron and Kenny: Statistical mediation analysis in the new millennium. Commun. Monogr. 2009, 76, 408-420. [CrossRef]

20. Drobot, S.D.; Benight, C.; Gruntfest, E.C. Risk factors for driving into flooded roads. Environ. Hazards 2007, 7, 227-234. [CrossRef]

21. Haynes, K.; Coates, L.; van den Honert, R.; Gissing, A.; Bird, D.; Dimer de Oliveira, F.; D’Arcy, R.; Smith, C.; Radford, D. Exploring the circumstances surrounding flood fatalities in Australia-1900-2015 and the implications for policy and practice. Environ. Sci. Policy 2017, 76, 165-176. [CrossRef]

22. Smith, G.P.; Modra, B.D.; Felder, S. Full-scale testing of stability curves for vehicles in flood waters. J. Flood Risk Manag. 2019, 12, 1-15. [CrossRef]

23. Coates, L. Flood fatalities in Australia, 1788-1996. Aust. Geogr. 1999, 30, 391-408. [CrossRef] 
24. Terti, G.; Ruin, I.; Anquetin, S.; Gourley, J.J. A situation-based analysis of flash flood fatalities in the United States. Bull. Am. Meteorol. Soc. 2017, 98, 333-345. [CrossRef]

25. Haynes, K.; Coates, L.; Leigh, R.; Handmer, J.; Whittaker, J.; Gissing, A.; Opper, S. 'Shelter-in-place' vs. evacuation in flash floods. Environ. Hazards 2009, 8, 291-303. [CrossRef]

26. Vinet, F.; Lumbroso, D.; Defossez, S.; Boissier, L. A comparative analysis of the loss of life during two recent floods in France: The sea surge caused by the storm Xynthia and the flash flood in Var. Nat. Hazards 2012, 61, 1179-1201. [CrossRef]

27. Carroll, B.; Morbey, H.; Balogh, R.; Araoz, G. Flooded homes, broken bonds, the meaning of home, psychological processes and their impact on psychological health in a disaster. Health Place 2009, 15, 540-547. [CrossRef]

28. Brunkard, J.; Namulanda, G.; Ratard, R. Hurricane Katrina Deaths, Louisiana, 2005. Disaster Med. Public Health Prep. 2008, 2, 1-9. [CrossRef]

29. Papathoma-Köhle, M.; Schlögl, M.; Fuchs, S. Vulnerability indicators for natural hazards: An innovative selection and weighting approach. Sci. Rep. 2019, 9, 15026. [CrossRef]

30. Diakakis, M.; Deligiannakis, G. Flood fatalities in Greece: 1970-2010. J. Flood Risk Manag. 2017, 10, 115-123. [CrossRef]

31. Diakakis, M. Types of behavior of flood victims around floodwaters. Correlation with situational and demographic factors. Sustainability 2020, 12, 4409. [CrossRef]

32. Vinet, F.; Boissier, L.; Saint-Martin, C. Flash flood-related mortality in southern France: First results from a new database. E3S Web Conf. 2016, 7, 06001. [CrossRef]

33. Anguelov, D.; Dulong, C.; Filip, D.; Frueh, C.; Lafon, S.; Lyon, R.; Ogale, A.; Vincent, L.; Weaver, J. Google street view: Capturing the world at street level. Computer 2010, 43, 32-38. [CrossRef]

34. Carrasco-Hernandez, R.; Smedley, A.R.D.; Webb, A.R. Using urban canyon geometries obtained from Google Street View for atmospheric studies: Potential applications in the calculation of street level total shortwave irradiances. Energy Build. 2015, 86, 340-348. [CrossRef]

35. Brouwer, T.; Eilander, D.; Van Loenen, A.; Booij, M.J.; Wijnberg, K.M.; Verkade, J.S.; Wagemaker, J. Probabilistic flood extent estimates from social media flood observations. Nat. Hazards Earth Syst. Sci. 2017, 17, 735-747. [CrossRef]

36. Mchugh, M.L. The Chi-square test of independence Lessons in biostatistics. Biochem. Med. 2013, 23, 143-149. [CrossRef] [PubMed]

37. Hellenic Statistical Authority. People Who Report Health Problem or Disability, by Type of Main Problem and Age; Springer: Athens, Greece, 2015.

38. Jonkman, S.N.; Vrijling, J.K. Loss of life due to floods. J. Flood Risk Manag. 2008, 1, 43-56. [CrossRef]

39. Wilson, T. Les risques de blessures et de décès par imprudence lors des inondations. Responsib. Environ. 2007, 43, 57-63.

40. Loke, A.Y.; Lai, C.K.Y.; Fung, O.W.M. At-home disaster preparedness of elderly people in Hong Kong. Geriatr. Gerontol. Int. 2012, 12, 524-531. [CrossRef]

41. Kozáková, R.; Tobolová, J.; Zeleníková, R. Perceived emotional and situational hearing handicap in the elderly and their family members. Cent. Eur. J. Nurs. Midwifery 2018, 9, 767-772. [CrossRef]

42. Gladwin, H.; Peacock, W.G. Warning and Evacuation: A Night for Hard Houses. In Hurricane Andrew: Ethnicity, Gender and the Sociology of Disasters; Florida International University: Miami, FL, USA, 1997; pp. 52-74.

43. Huerta, F.; Horton, R. Coping behavior of elderly flood victims. Gerontologist 1978, 18, 541-546. [CrossRef]

44. Kelman, I. Decision-Making for Flood-Threatened Properties. In Flood Risk Management in Europe; Begum, S., Stive, M.J., Hall, J.W., Eds.; Springer: Dordrecht, The Netherlands, 2007; Volume 53, pp. 3-20, ISBN 9788578110796.

45. Granbom, M.; Perrin, N.; Szanton, S.; Cudjoe, T.K.M.; Gitlin, L.N. Household Accessibility and Residential Relocation in Older Adults. J. Gerontol. Ser. B Psychol. Sci. Soc. Sci. 2019, 74, e72-e83. [CrossRef]

46. Kelman, I.; Spence, R. An overview of flood actions on buildings. Eng. Geol. 2004, 73, 297-309. [CrossRef]

47. Hellenic Statistical Authority Greek Population-Housing Census 2011 [Internet]. 2011. Available online: https://www.statistics. gr/en/2011-census-pop-hous (accessed on 15 July 2021).

48. Petrucci, O.; Aceto, L.; Bianchi, C.; Bigot, V.; Br, R.; Pereira, S.; Kahraman, A.; Kılıç, Ö.; Kotroni, V.; Llasat, M.C.; et al. Flood Fatalities in Europe, 1980-2018: Variability, Features, and Lessons to Learn. Water 2019, 11, 1682. [CrossRef]

49. Smith, G.P.; Rahman, P.F. Approaches for Estimating Flood Fatalities Relevant to Floodplain Management; Springer: Manly Vale, Australia, 2016. 